\title{
Metal-Organic Frameworks for Mercury Sensing and Removal
}

\author{
Xuan Wang* and Jillian N. Manikoff \\ Department of Chemistry, Colorado State University-Pueblo, 2200 Bonforte Blvd, Pueblo, \\ CO 81001, the United States \\ Email: aggiewangx@gmail.com (X.W.)
}

\begin{abstract}
Removal of mercury contaminants from nature receives a global attention from a biological and environmental standpoint. Recently, metal-organic frameworks (MOFs) show much promises in the adsorptive removal of mercury species. This review summarizes the recent studies on the MOF-based materials for mercury sensing and removal. The design of those materials are listed in five categories-use of unfunctionalized MOFs, linker design of MOFs, modification of MOF system, post-synthetic modification of the frameworks, and development of MOF-based composites. Finally, several key learning points are discussed in the aim of a facilitating new design of MOF-based sensors and adsorbents for mercury.
\end{abstract}

Keywords metal-organic frameworks, Hg sensing and removal, linker design, post-synthetic modification, composites

\section{Introduction}

Mercury contamination in water and soil receives growing awareness due to its toxicity even at very low concentration. In nature, mercury mainly exists as inorganic $\left(\mathrm{Hg}^{2+}\right)$, organic $\left(\mathrm{CH}_{3} \mathrm{Hg}^{+}\right.$, primarily), and elemental $\left(\mathrm{Hg}^{0}\right)$ forms, as well as complexes. Mercury is in our daily life, from coal, paint, batteries, and any electronic equipment to name a few, which could be easily spread out to nature through human activities. One of the major toxicities is the accumulation of mercury in the human body through the food chain, which could ultimately lead to cardiovascular disease, heart disease, serious cognitive and motion disorders, and even renal failure. Additionally, the World Health Organization recommends the standard $\mathrm{Hg}$ level in drinking water should be less than $1 \mathrm{ppb}$. Therefore, designing facile, cheap, portable mercury sensors with fast response is an important task from the consideration of human health and environmental concerns. More importantly, high-performing and cost-efficient mercury adsorbents are in urgent needs to remove the mercury contaminants from the environment, especially the natural water.

Over the years, technologies, such as chemical precipitation, ${ }^{[1]}$ membrane, ${ }^{[2]}$ ion exchange, ${ }^{[3]}$ liquid extraction, ${ }^{[4]}$ and adsorption, ${ }^{[5]}$ have been developed to remove and recovery the mercury species from nature. Among all the techniques, adsorption, the adhesion of atoms, molecules or ions to the surface of a material, stands out due to its simplicity. In general, the adsorption could be divided into the physical and chemical adsorption based on the interactions between adsorbate and adsorbent (usually porous). The adsorbate is typically trapped in the adsorbents by van der Waals forces, which is known as physisorption. The degree of physisorption depends highly on the interaction sites, which is based on the nature of both adsorbent and adsorbate. One of the advantages of physisorption is the ease of regeneration, which could be achieved by simple heat treatment or ion/solvent exchange. In this case, porous material with high surface area with suitable pore size will be an ideal adsorbent. On the other hand, increasing the chemisorp- tion will theoretically increase the overall capacity of adsorbate, which enhances ultimately the removal efficiency in the case of mercury. In order to provide such chemisorption beyond physisorption, a good adsorbent for mercury should consist of mercury-favored groups. Herein, metal-organic frameworks (MOFs) offer both flexibility and accommodation to satisfy these two requirements. In many cases, the adsorption of guest species (mercury in this review) in the MOF-based material alters significantly the chemical and physical properties of the framework, which also promises MOFs as potential probes to sense various species.

MOFs, also known as porous coordination polymers, are superior porous materials because of their high surface area, huge porosity, and capability for functionalization. Tremendous efforts have been spent on the utilization of MOFs in the field of material science and biomedical technology. ${ }^{[6-20]}$ Moreover, a significant amount of studies focus on the modification of MOFs to tune precisely the chemical and physical properties via topological guidance, linker design, post-synthetic modification, and construction of MOF-based composites. ${ }^{[21-29]}$ Those successful cases are excellent references for designing the new mercury sensor/adsorbent.

This review will outline the use of MOF-related materials as $\mathrm{Hg}$ sensors and/or adsorbents. The special design of the MOFbased system will be pointed out. Those special design will be summarized into five catalogues-unfunctionalized MOFs, linker design of MOFs, modification of MOF system, post-synthetic modification (PSM) of MOFs, and MOF-based composite. Each category is further grouped based on the purpose of mercury sensing or mercury removal. The known examples of using MOF-related materials as $\mathrm{Hg}$ sensors/adsorbents are listed in Table S1 (see Supporting Information) in terms of design, mercury capacity, removal efficiency, degree of luminescence quenching, recovery from real samples for each MOF. Moreover, a couple of key learning points will be summarized in the Conclusion and Outlook as further reference to design new MOF-related sensors/adsorbents for mercury. 


\section{Review}

\section{MOF-based adsorbents for mercury sensing and removal}

\section{Use of unfunctionalized MOFs}

\section{Mercury sensing}

Wang and coworkers ${ }^{[30]}$ developed a MOF Complex 1 with 5,5'-[ethane-1,2-diylbis(oxy)]diisophthalic acid $\left(\mathrm{H}_{4}\right.$ EDDA) as the ligand. Compare to the solid-state UV-Vis spectra of free $\mathrm{H}_{4}$ EDDA ligand, the maximum emission at $350 \mathrm{~nm}$ based on the charge transfer between ligand and metal significantly decreased, while the ligand-based emission at $410 \mathrm{~nm}$ became conspicuous after immersing Complex 1 into the $\mathrm{Hg}^{2+}$ solution. The detection limit (LOD) of Complex 1 was below $2 \mathrm{nM}$, and $K_{\mathrm{sv}}$ was calculated to be $4.3 \times 10^{3} \mathrm{M}^{-1}$. The mechanism studies concluded from the FT-IR spectra and electrospray ionization MS measurements implied that introduction of $\mathrm{Hg}^{2+}$ induced the collapse of Complex 1 , regenerating free $\mathrm{H}_{4}$ EDDA to interact with $\mathrm{Hg}^{2+}$. Besides, this study also demonstrated that Complex 1 was highly selective for $\mathrm{Hg}^{2+}$ in presence of alkali, alkalineearth or other transition metals, such as $\mathrm{Li}^{+}, \mathrm{Na}^{+}, \mathrm{K}^{+}, \mathrm{Mg}^{2+}, \mathrm{Ca}^{2+}$, $\mathrm{Sr}^{2+}, \mathrm{Ba}^{2+}, \mathrm{Mn}^{2}, \mathrm{Zn}^{2+}, \mathrm{Fe}^{2+}, \mathrm{Co}^{2+}, \mathrm{Ni}^{2+}, \mathrm{Ag}^{+}, \mathrm{Cu}^{2+}, \mathrm{Cd}^{2+}$, and $\mathrm{Pb}^{2+}$.

Wen and coworkers ${ }^{[31]}$ used 2-amino-1,4-benzene-dicarboxylic acid (2- $\mathrm{NH}_{2}$ bdc) with coligands-4,4'-bis(imidazole-1ylmethyl)-biphenyl (bibp) and 1,3,5-tris(1-imidzolyl)-benzene (tib), to obtain two MOFs Complex 2 ([Zn(2-- $\left.\left.\left.\mathrm{NH}_{2} \mathrm{bdc}\right)(\mathrm{bibp})\right]_{n}\right)$ and Complex $3\left(\left[\mathrm{Cd}\left(2-\mathrm{NH}_{2} \mathrm{bdc}\right)(\mathrm{tib}) \cdot 4 \mathrm{H}_{2} \mathrm{O} \cdot 0.5 \mathrm{DMA}\right]_{n}\right)$, respectively. Complex 2 was a 5 -fold interpenetrated MOF, while Complex $\mathbf{3}$ was a 2-fold interpenetrated MOF. Complex 2 displayed a diminishing blue emission when treated with an increasing concentration of $\mathrm{Hg}^{2+}$. XPS study revealed the $\mathrm{N}$ atoms of $2-\mathrm{NH}_{2}$ bdc chelated to $\mathrm{Hg}^{2+}$ ions, which enabled Complex 2 to have a quenching constant $K_{\mathrm{sv}}$ of $4550 \mathrm{M}^{-1}$. Among all the ions of $\mathrm{NH}_{4}^{+}, \mathrm{Na}^{+}, \mathrm{K}^{+}, \mathrm{Mg}^{2+}, \mathrm{Ca}^{2+}, \mathrm{Sr}^{2+}, \mathrm{Ba}^{2+}, \mathrm{Ag}^{+}, \mathrm{Zn}^{2+}, \mathrm{Hg}^{2+}$, $\mathrm{Cd}^{2+}, \mathrm{Cl}^{-}, \mathrm{F}^{-}, \mathrm{Br}^{-}, \mathrm{I}^{-}, \mathrm{ClO}_{4}^{-}, \mathrm{HCO}_{3}^{-}, \mathrm{NO}_{3}^{-}, \mathrm{NO}_{2}^{-}, \mathrm{H}_{2} \mathrm{PO}_{4}^{-}, \mathrm{OAc}^{-}$, $\mathrm{SO}_{4}{ }^{2-}, \mathrm{CO}_{3}{ }^{2-}, \mathrm{PO}_{4}{ }^{3-}$, and $\mathrm{Cr}_{2} \mathrm{O}_{7}{ }^{2-}$, only $\mathrm{Hg}^{2+}$ and $\mathrm{Cr}_{2} \mathrm{O}_{7}{ }^{2-}$ gave the most significant emission suppressions. In addition, the detection limit of mercury for Complex 3 reached $4.2 \times 10^{-8} \mathrm{M}$.

Suresh group ${ }^{[32]}$ utilized the nucleobase adenine to construct Complex $4\left(\left[\mathrm{Zn}\left(\mu_{2}-1 \mathrm{H}\right.\right.\right.$-ade $\left.\left.)\left(\mu_{2}-\mathrm{SO}_{4}\right)\right]\right)$ as a $\mathrm{Hg}^{2+}$ sensor. Complex 4 exhibited a ligand-based photoluminescence at 413 $\mathrm{nm}$ (vs. $416 \mathrm{~nm}$ for adenine) with the excitation at $295 \mathrm{~nm}$. Among the cationic mixture containing $\mathrm{Zn}^{2+}, \mathrm{Cd}^{2+}, \mathrm{Cs}^{+}, \mathrm{Ba}^{2+}$, $\mathrm{Cu}^{2+}, \mathrm{Na}^{+}, \mathrm{K}^{+}, \mathrm{Pb}^{2+}, \mathrm{Co}^{2+}, \mathrm{Mn}^{2+}, \mathrm{Ca}^{2+}, \mathrm{Mg}^{2+}, \mathrm{Cr}^{3+}, \mathrm{Hg}^{2+}$ or $\mathrm{As}_{2} \mathrm{O}_{3}$, only $\mathrm{Hg}^{2+}$ quenched almost completely the emission band, with quenching constant $K_{\mathrm{sv}}$ value of $7.7 \times 10^{3} \mathrm{M}^{-1}$. As the addition of $\mathrm{Hg}^{2+}$ (0.05-1.0 mM) increased, the emission intensity of Complex 4 decreased linearly. The LOD of $\mathrm{Hg}^{2+}$ reached $70 \mathrm{nM}$ in water. It was believed that the coordination between the free $\mathrm{N}$ atoms from the adenine in Complex 4 and $\mathrm{Hg}^{2+}$ led to the reduction of luminescence intensity.

The effects on the utilization of $\mathrm{N}$-containing heterocyclic linkers also show enhanced performance for mercury sensing. Lang, Li, Brammer, and coworkers ${ }^{[33]}$ constructed Complex 5 [Zn(ppvppa)(1,4-NDC) $]_{n}$, where ppvppa abbreviated for di-pyridin-2-yl-[4-(2-pyridine-4-yl-vinyl)-phenyl]-amine and 1,4- $\mathrm{H}_{2} \mathrm{NDC}$ was 1,4-napthalenedicarboxylic acid. In this network, the basic unit $\mathrm{Zn}_{2}$ (ppyppa) $)_{2}$, where each $\mathrm{Zn}$ ion coordinated tetrahedrally to two $\mathrm{O}$ atoms from the NDC linkers and two $\mathrm{N}$ atoms from the ppyppa linkers, was further interlinked by $1,4-N D C$ to produce a honeycomb network. As a result, the uncoordinated $\mathrm{N}$ atoms of the ppyppa linkers, which was also observed in their previous nitroaromatic sensing work, ${ }^{[34]}$ promised the chelating with other metal ions $\left(\mathrm{Hg}^{2+}\right.$ and $\mathrm{MeHg}^{+}$in this case). The ppyppa ligand demonstrated excellent colorimetric chemosensing ability evident by the diminishing fluorescence peak at $460 \mathrm{~nm}$ and the growing new peaks at $580 \mathrm{~nm}$ along with the addition of $\mathrm{Hg}^{2+}$. The coordination between the $\mathrm{N}$ atoms of ppyppa and $\mathrm{Hg}^{2+}$ was further confirmed by ${ }^{1} \mathrm{H}$ NMR titration. The quenching effects of $\mathrm{Hg}^{2+}$ was much more significant than any other ions, such as $\mathrm{Na}^{+}, \mathrm{K}^{+}, \mathrm{Zn}^{2+}, \mathrm{Co}^{2+}, \mathrm{Ni}^{2+}, \mathrm{Cu}^{2+}, \mathrm{Cd}^{2+}, \mathrm{Mn}^{2+}$, and $\mathrm{Pb}^{2+}$. Moreover, the researchers adopted Complex $\mathbf{5}$ for the mercury sensing. Only the coordination with $\mathrm{Hg}^{2+}$ and $\mathrm{MeHg}^{+}$displayed not only a blue shift of one of the emission maximum peaks but also a decrease of the other emission peak, leading to a color change from pale orange to blue.

Another work from the same group later reported the synthesis of five different $\mathrm{Zn}$-based MOFs using another pyridine-appended ligand1,4-bis(2-pyrindin-4-yl)-vinyl)naphthalene (1,4-bpyna) with coligand of 1,3,5-benzene-tricarboxylate acid $\left(1,3,5-\mathrm{H}_{3} \mathrm{BTC}\right)$ or $4,4^{\prime}-\mathrm{H}_{2} \mathrm{OBA}{ }^{[35]}$ The 1,4-bpyna ligand demonstrated itself excellent colorimetric probing ability evident by quenching the fluorescence band at $446 \mathrm{~nm}$ and the emission band at $471 \mathrm{~nm}$ along with a growth of a small peak at $510 \mathrm{~nm}$ along with the addition of $\mathrm{Hg}^{2+}$. The ${ }^{1} \mathrm{H}$ NMR titration results approved that $\mathrm{Hg}^{2+}$ coordinated to the $\mathrm{N}$ atoms of 1,4-bpyna, inducing the intramolecular charge transfer and quenching the fluorescence. Moreover, the sensing ability of one of the five polymer Complex 6, $\left[\mathrm{Zn}_{2}(1,4-\text { bpyna })(1,3,5-\mathrm{BTC})(\mathrm{OH})\right]_{n}$ was also tested. No significant fluorescence change of Complex 6 was observed in the presence of $\mathrm{Na}^{+}, \mathrm{Ag}^{+}, \mathrm{Ba}^{2+}, \mathrm{Mn}^{2+}, \mathrm{Cd}^{2+}$, $\mathrm{Co}^{2+}, \mathrm{Ni}^{2+}$, and $\mathrm{Cu}^{2+}$. However, the addition of $\mathrm{Hg}^{2+}$ quenched the emission at 444 and $472 \mathrm{~nm}$ with a growth of new and broad peak at $520 \mathrm{~nm}$, leading to a visible color change from blue to yellow. The quenching constant $K_{\mathrm{sv}}$ was reported with a value of $3.23 \times 106 \mathrm{M}^{-1}$ with the detection limit of $0.057 \mathrm{ppm}$. Additionally, Complex 6 demonstrated recyclability without loss of fluorescence intensity after six cycles.

Rossin group ${ }^{[36]}$ used $m$-(2-thiazolyl)benzoic acid and $\mathrm{Zn}^{2+}$ with different basic auxiliary ligands, such as 4,4'-dipyridyl (bpy) and 1.2-bis(4-pyridly)ethane (PyEtPy), to develop four Zn-based MOFs (Complex 7-10). In Complex 7 and 10, the dangling $\mathrm{N}$ atoms from the thiazole-based linkers coordinated to the $\mathrm{Hg}^{2+}$ ions in aqueous solution and induced ultimate quenching of the thiazole-based luminescence along with a partial polymer aggregation.

Cui, Qian, and coworkers ${ }^{[37]}$ utilized the ligand 4,4',4"'-s-triazine-1,3,5-triyltri-p-aminobenzoic acid $\left(\mathrm{H}_{3} \mathrm{TATAB}\right)$ and $\mathrm{Ln}^{3+}$ $(\mathrm{Ln}=\mathrm{Eu}, \mathrm{Tb}, \mathrm{Sm}, \mathrm{Dy}, \mathrm{Gd})$ ions to synthesize a series of LnTATAB MOF. The series of MOFs were all constructed with 1D Ln-carboxylate chain with 1D rhombic channel with the dimensions of around $27 \times 23 \AA^{2}$, which turned out to be beneficial for the diffusion and accumulation of $\mathrm{Hg}^{2+}$ in the framework. Among all the Ln-TATAB MOFs, Complex 11 (Tb-TATAB) exhibited not only good water stability but also high quantum yield for its photoluminescence, which promised it as a potential mercury sensor. The detection limit of $\mathrm{Hg}^{2+}$ for Complex 11 was estimated to $4.4 \mathrm{nM}$. Furthermore, only $\mathrm{Hg}^{2+}$ caused a significant luminescence quenching $\left(K_{\mathrm{sv}}=4851 \mathrm{M}^{-1}\right)$ for Complex 11 in the presence of other ions, such as $\mathrm{Zn}^{2+}, \mathrm{Mg}^{2+}, \mathrm{Ni}^{2+}, \mathrm{Na}^{+}$, $\mathrm{Ca}^{2+}, \mathrm{Cr}^{3+}, \mathrm{Mn}^{2+}, \mathrm{Co}^{2+}, \mathrm{Pb}^{2+}, \mathrm{Cd}^{2+}, \mathrm{Cu}^{2+}$, and $\mathrm{Fe}^{3+}$. The high affinity of $\mathrm{Hg}^{2+}$ towards the $\mathrm{N}$ atoms of TATAB disturbed the antenna effect of TATAB towards to $\mathrm{Tb}^{3+}$. Thanks to the high selectivity of $\mathrm{Hg}^{2+}$, Complex 11 was successfully applied to detect the concentration of $\mathrm{Hg}^{2+}$ in samples of river water, drinking water, and tap water with more than $95 \%$ recovery with standard derivation (STD) smaller than $5 \%$.

Yang group ${ }^{[38]}$ obtained a luminescent MOF Complex 12 $\left(\left[\mathrm{TbL}_{1.5}\left(\mathrm{H}_{2} \mathrm{O}\right)_{2}\right] \mathrm{H}_{2} \mathrm{O}\right)$, which was prepared using 5-(3'-carboxylphenyl)nicotinic acid $\left(\mathrm{H}_{2} \mathrm{~L}\right)$ and $\mathrm{Tb}^{3+}$. It was found that $\mathrm{Hg}^{2+}$ ions showed better affinity to the free pyridyl $\mathrm{N}$ atoms and the $\mathrm{Hg}-\mathrm{N}$ coordination consequently quenched significantly the lumines- 
General Chemistry

cent intensity of Complex 12 at $545 \mathrm{~nm}$. At the same time, other ions, such as $\mathrm{Ba}^{2+}, \mathrm{Mg}^{2+}, \mathrm{Ca}^{2+}, \mathrm{Co}^{2+}, \mathrm{Cd}^{2+}, \mathrm{Zn}^{2+}, \mathrm{Ni}^{2+}, \mathrm{Cu}^{2+}$, and $\mathrm{Pb}^{2+}$, displayed much less influence on the intensity. To describe the quenching sensitivity, $K_{\mathrm{sv}}$ was measured with a value of $7465 \mathrm{M}^{-1}$. In addition, Complex 12 exhibited reusability up to five times with only $12.2 \%$ decrease of luminescent intensity along the way.

Wang, Long and coworkers ${ }^{[39]}$ used Complex 13 (ZIF-7) and Complex 14 (ZIF-60) to probe $\mathrm{Hg}^{2+}$ and $\mathrm{CH}_{3} \mathrm{Hg}^{+}$species, respectively. Interestingly, the fluorescence intensity decayed with an increasing concentration of $\mathrm{Hg}^{2+}$ for Complex 13 while enhanced with an increasing concentration of $\mathrm{CH}_{3} \mathrm{Hg}^{+}$for Complex 14, even in the presence of other ions. The authors attributed the different influences to the facts that $\mathrm{Hg}$ interacted with the $\mathrm{N}$ atoms of Complex 13 prevented the electron transfer, while the $\mathrm{CH}_{3} \mathrm{Hg}^{+}$inhibited the linker motion, slowed down the nonradioactive decay process, and increased the decaying of excited species. The detection limit of $\mathrm{Hg}^{2+}$ was $3 \mathrm{ng} / \mathrm{mL}$ for Complex 13, and that of $\mathrm{CH}_{3} \mathrm{Hg}^{+}$was $6 \mathrm{ng} / \mathrm{mL}$ for Complex 14 . The researchers further used Complex 13 and Complex 14 in the local drinking water samples to preconcentrate $\mathrm{Hg}^{2+}$ and $\mathrm{CH}_{3} \mathrm{Hg}^{+}$, respectively. It turned out that the recoveries were $102 \%$ and $96.2 \%$, respectively.

Using another porotype MOFs Complex 15 (Cr-MIL-101), Guo group ${ }^{[40]}$ found the detection limit was $8.8 \mathrm{nM}$.

In the study of using Complex 16 (PCN-222/MOF-454), the researchers found the maximum capacity with the value of 35 $\mathrm{mg} / \mathrm{g}$ and the limit of detection $0.02 \mu \mathrm{g} / \mathrm{L} .{ }^{[41]}$ Most of the $\mathrm{Hg}^{2+}$ recovery percentage of Complex 16 was more than $98 \%$ from three real fish samples under the optimal conditions. Significantly, Complex 16 can be reused for 15 times without decrease of extraction recoveries.

As the PCN-2XX series show good stability, Gu group ${ }^{[42]}$ utilized Complex 17 (PCN-224), constructed with meso-tetra(4-carboxyphenyl)porphyrin as the bridging structs, as a $\mathrm{Hg}^{2+}$ sensor. The ligand-based florescence of Complex 17 showed a strong emission peak at $651 \mathrm{~nm}$ with a weak shoulder at 705 $\mathrm{nm}$. The addition of $\mathrm{Hg}^{2+}$ introduced a reverse photoinduced electron transfer by coordinating to the $\mathrm{N}$ atoms of porphyrin in an out-of-plane mode and quenched the red emission within 2 min. The $K_{\mathrm{sv}}$ constant for Complex 17 was calculated to be $6.4 \times 10^{5} \mathrm{M}^{-1}$ and the detection limit was $6 \mathrm{nM}$. The variation of $\mathrm{Hg}^{2+}$ concentration changed the color of Complex 17 gradually from purple to light green due to the charge transfer in the porphyrin-Hg complex, which could be easily distinguished by naked eye. Moreover, no obvious perturbation was overserved when other ions, such as $\mathrm{Al}^{3+}, \mathrm{Ca}^{2+}, \mathrm{Cu}^{2+}, \mathrm{Fe}^{3+}, \mathrm{Mg}^{2+}, \mathrm{Ni}^{2+}, \mathrm{K}^{+}$, $\mathrm{Na}^{+}$, and $\mathrm{Zn}^{2+}$, were further introduced in the system. Furthermore, the $\mathrm{Hg}^{2+}$ species in Complex 17 could be easily recovered by adding $\mathrm{I}^{-}$, which had a high binding affinity towards $\mathrm{Hg}^{2+}$. Due the ease synthesis, excellent stability, and facile regeneration, the researchers also applied Complex 17 as the probe in tap, distilled, and river water samples. The resultant recoveries maintained in the high range from $96 \%-104 \%$.

\section{Mercury removal}

Roy and coworkers ${ }^{[43]}$ synthesized Complex 18 ([Ni(3bpd $\left.)_{2}(\mathrm{NCS})_{2}\right]_{n}$ ), where the $\mathrm{Ni}$ ion coordinated octahedrally with four nitrogen atoms of the pyridine-based linkers in the equatorial position and two nitrogen atoms of the thiocyanato moieties in the apical positon. Notably, the sulfur atoms of thiocyanato remained uncoordinated. After immersing Complex 18 into the $\mathrm{Hg}^{2+}$ solution, the sulfur coordinated to $\mathrm{Hg}$ atom with the evidence of increasing wavenumber of IR peaks $\left(2138 \mathrm{~cm}^{-1} \mathrm{vs}\right.$. $2069 \mathrm{~cm}^{-1}$ for thiocyanato groups in Complex 18) due to the decreasing electron density on sulfur. As a result, Complex 18 turned from green to grey $(\mathrm{Ni}: \mathrm{Hg}=1: 2)$ with the naked eye. Complex 18 also demonstrated $94.3 \%$ removal efficiency with initial $\mathrm{Hg}$ concentration of $10 \mu \mathrm{g} \cdot \mathrm{L}^{-1}$ and a maximum mercury capacity of $713 \mathrm{mg} / \mathrm{g}$.

Zhou group ${ }^{[44]}$ developed two nitrogen-rich MOFs, Complex 19 (PCN-100) and Complex 20 (PCN-101), which were built on zinc paddle-wheels with 4,4',4"'-s-triazine-1,3,5-triyltri-p-aminobenzoate (TATAB), and benzene-1,3,5-triyltris(azanediyl)-tribenzoate (BTATB), respectively. They found that Complex 20 captured $0.61 \mathrm{Hg}$ per formula unit, while Complex 19 increased the capacity to $1.38 \mathrm{Hg}^{2+}$ per formula unit due to the coordination of aminopyridinato to $\mathrm{Hg}^{2+}$.

Hu's group ${ }^{[45]}$ utilized Complex 21 (JUC-62) constructed from 3,3',5,5'-azobenzenetetracarboxylate and copper paddlewheel to preconcentrate $\mathrm{Hg}^{2+}$ in agricultural products. The nitrogen-richness and mesoporous nature endorsed Complex 21 with the maximum adsorption capacity for $\mathrm{Hg}^{2+}$ of $836.7 \mathrm{mg} / \mathrm{g}$. The removal efficiency of $\mathrm{Hg}^{2+}$ was $\sim 80 \%$, which was much higher compared to those of $\mathrm{Pb}^{2+}, \mathrm{Cr}^{6+}, \mathrm{Cd}^{2+}, \mathrm{Ca}^{2+}, \mathrm{Mg}^{2+}, \mathrm{Fe}^{3+}$, $\mathrm{Zn}^{2+}, \mathrm{Na}^{+}$, and $\mathrm{K}^{+}$. In the preconcentration of the black tea and mushroom samples, Complex 21 recovered successfully $\sim 94.0 \%$ and $90.0 \% \mathrm{Hg}^{2+}$, respectively.

Zhang group ${ }^{[46]}$ investigated the adsorption ability of Complex 22 (MOF-74-Zn). They found the maximum $\mathrm{Hg}^{2+}$ uptake reached to $63 \mathrm{mg} / \mathrm{g}$ at $\mathrm{pH}=6$ via both physisorption and chemisorption (the hydroxyl sites). Complex 22 showed the removal efficiencies of $54.48 \%, 69.71 \%$, and $72.26 \%$ at the $\mathrm{Hg}$ concentrations of $20,40,50 \mathrm{ppb}$, respectively. They also found increasing the adsorption temperature increased the overall mercury uptake of Complex 22, since the adsorption of mercury was an endothermic monolayer reaction.

In the last few years, the exploration of Zr-based MOFs becomes a hot topic in the field due to the fact that the strong coordination between $\mathrm{Zr}^{4+}$ and carboxylate produces multiple hydrophobic $\mathrm{Zr}-\mathrm{O}$ units and endorses the corresponding MOFs with great stability. Shen and coworkers ${ }^{[47]}$ constructed the bromine-based analogues of Complex 23 (UiO-66), namely Complex 24 (UiO-66-Br) and Complex 25 (UiO-66-2Br), using bromine derivatives of 1,4-benzendicarboxylic acid as the ligands. During a five-hour period, the removal efficiencies of $\mathrm{Hg}^{0}$ from the flue gas at $200{ }^{\circ} \mathrm{C}$ dropped from $96.0 \%$ to $52.2 \%$ and from $100 \%$ to $80 \%$ for Complex 23 and Complex 24, respectively. However, Complex 25 retained its removal efficiency as $100 \%$ for $48 \mathrm{~h}$. It was clear that the two bromine atoms on the phenyl ring attributed predominately to the steady removal efficiency during a long period of time. The highest accumulative adsorption amount of Complex 25 was $302 \mu \mathrm{g} / \mathrm{g}$. Notably, the exposure of the MOF sorbents to $\mathrm{SO}_{2}$ enhanced the $\mathrm{Hg}^{\circ}$ adsorption, while the presence of $\mathrm{H}_{2} \mathrm{O}$ destroyed the crystalline structure and prohibited the adsorption.

\section{Linker design to construct MOFs}

\section{Mercury sensing}

Linker design has been approved to be one of the most efficient ways to improve the sensitivity and selectivity of a MOFbased sensor. ${ }^{[21]}$ Following this thought, Lai et al. ${ }^{[48]}$ found the fluorescent 2, 9-dimethyl-1,10-phenathroline (2,9-DMP) was an excellent probe to sense $\mathrm{Hg}^{2+}$ in water samples. As a result, they achieved Hg-based MOFs Complex 26. Among 19 ions, only the coordination between $\mathrm{Hg}^{2+}$ and DMP almost quenched the fluorescence of DMP. Besides, the DMP linker exhibited high $\mathrm{Hg}$-sensitivity in a fast rate within $20 \mathrm{~s}$.

\section{Mercury removal}

Later, more studies were focused on the incorporation of sulfur-containing groups, thiol and thioether in particular, on the framework. Since sulfur shows a high affinity towards mercury, an inclusion of sulfur-containing groups could increase the mercury capacity as well as the removal efficiency. Xu group ${ }^{[49]}$ 
reported the free-standing thioether groups in Complex 27 constructed from tetrakis(methylthiol)-1,4-benzenedicar-boxylic acid (TMBD) and $\mathrm{Pb}^{2+}$. Complex 27 could adsorb $\mathrm{Hg}^{2+}$ with the maximum ratio of $\mathrm{Pb}: \mathrm{Hg}=1: 1$. Majority of adsorbed $\mathrm{Hg}^{2+}$ in Complex 27 could be easily removed using acetonitrile.

Similarly, exposed 2-methylthioethylthio side chain $\left(-\mathrm{SCH}_{2}-\right.$ $\mathrm{CH}_{2} \mathrm{SCH}_{3}$ ) was introduced into the cavity of MOF-5 to achieve Complex 28 (MOF-5-SCH $\mathrm{CH}_{2} \mathrm{SCH}_{3}$ ). ${ }^{[50]}$ The extended thioether chain significantly red-shifted the emission wavelength to $500 \mathrm{~nm}$ with a weaker side peak at $410 \mathrm{~nm}$ (vs. 390 $\mathrm{nm}$ for unfunctionalized ligand). At the same time, Complex 28 displayed the emission wavelength at $475 \mathrm{~nm}$ with a side peak at $410 \mathrm{~nm}$. The flexible thioether chain enhanced the accessibility for the incoming $\mathrm{Hg}^{2+}$ ions. However, the mercury capture of Complex 28 suppressed $90 \%$ of the original emission, which made it barely visible. The mercury uptake reached the $\mathrm{Zn}: \mathrm{Hg}$ ratio of 5.56:1. Immersing $10 \mathrm{mg}$ Complex 28 in $2.0 \mathrm{~mL} \mathrm{HgCl}$ in ethanol solution (84 $\mathrm{mg} / \mathrm{L})$, the removal efficiency was over $94 \%$ after six days.

Another similar study was based on Complex 29 (FJI-H12Co), which consisted of 2,4,6-tri(1-imidazolyl)-1,3,-5-triazine (Timt), NCS- and $\mathrm{Co}^{2+}{ }^{[51]}$ In Complex 29, the exposed sulfur was pointing to the cavity, which promised Complex 29 a good selectivity of $\mathrm{Hg}^{2+}$ over other common metal ions (except $\mathrm{Cd}^{2+}$ ) with a maximum mercury capacity of $439.8 \mathrm{mg} / \mathrm{g}$. The IR shift at 2072-2125 $\mathrm{cm}^{-1}$ revealed that chemisorption from the exposed sulfur sites of $\mathrm{NCS}^{-}$to $\mathrm{Hg}^{2+}$ contributed to the overall mercury capacity. Interestingly, the researched also packed $2 \mathrm{~g} \mathrm{Com-}$ plex 29 into a $10 \mathrm{~mL}$ syringe, and this MOF-filled column was capable to purify a $50 \mathrm{~mL}$ solution with the concentration of 20 ppm.

Thanks to the stability of $\mathrm{Zr}$-O clusters, $\mathrm{Zr}$-based MOFs are an attracting class of MOF as platforms for most types of modifications. As an example, thiol groups was introduced to UiO-66 to produce Complex 30 (UiO-66-SH), shown in Figure 1. ${ }^{[52]}$ After immersing $10 \mathrm{mg}$ Complex 30 in $10 \mathrm{~mL} 10 \mathrm{ppb} \mathrm{Hg}\left(\mathrm{NO}_{3}\right)_{2}$ solution for $12 \mathrm{hrs}$, the removal efficiency was over $99.9 \%$. The maximum mercury capacity reached $\mathrm{Zr}: \mathrm{Hg}=6: 1.82$. Further studies of the adsorption showed that IR peaks at $2560 \mathrm{~cm}^{-1}$, indicating $\mathrm{S}-\mathrm{H}$ stretching, disappeared with the appearance of peaks at $355 \mathrm{~cm}^{-1}$ for the $\mathrm{Hg}-\mathrm{S}$ stretching. In the $\mathrm{Hg}$ vapor test, the adsorption of $\mathrm{Hg}$ vapor suppressed significantly the photoluminescence of Complex 30, which could hardly be seen by eye (vs. a near-white emission for Complex $\mathbf{3 0}$ itself.)
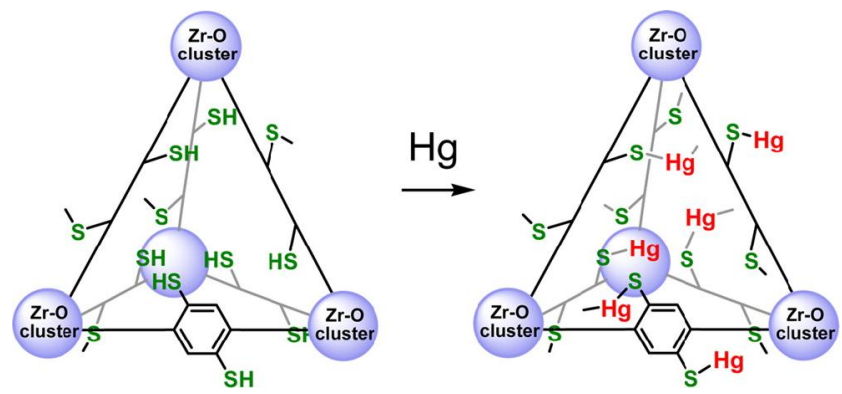

Figure 1 Thio-modified Complex 30. ${ }^{[52]}$

Later, Liu and coworkers ${ }^{[53]}$ fabricated a stable MOF Complex 31 (Zr-DTDC) using 3,3-dimethylthieno[2,3-b]thiophene2,5-dicarboxylic acid ( $\left.\mathrm{H}_{2} \mathrm{DTDC}\right)$ as the ligand. Complex 31 was successfully used to capture the $\mathrm{Hg}^{0}$ vapor with a distinct color change from white to yellow. The $\mathrm{Hg}^{0}$ vapor was believed to coordinate to the thiophene part of the linkers and suppressed $\sim 70 \%$ of the photoluminescence emission of Complex 31. Interestingly, the binding energy of $\mathrm{Hg} 4 \mathrm{f} 7 / 2$ shifted to $101.3 \mathrm{eV}$ (vs. $99.9 \mathrm{eV}$ for $\mathrm{Hg}^{0}$ ), indicating a chemisorption of $\mathrm{Hg}^{0}$.

Beside of the sulfur-containing groups, researchers also utilized acylamide and hydroxyl groups in MOFs to adsorb $\mathrm{Hg}^{2+}$ species. ${ }^{[54]}$ Luo and coworkers developed Complex 32 [Zn(hip)(L).(DMF) $\left.\left(\mathrm{H}_{2} \mathrm{O}\right)\right]$, where $\mathrm{H}_{2}$ hip=5-hydroxyisophthalic acid and $\mathrm{L}=N^{4}, N^{4^{\prime}}$-di(pyridine-4-yl)biphenyl-4,4'-dicarboxamide. The hydroxyl and acylamide group attracted strongly $\mathrm{Hg}^{2+}$ through chemisorption, leading to a maximum capacity of 278 $\mathrm{mg} \cdot \mathrm{g}^{-1}$ and maximum removal efficiency to $84.76 \%$ when the initial concentration was $20 \mathrm{ppb}$.

In addition, Li group ${ }^{[55]}$ developed three ligand-based luminescent MOFs, namely LMOF-261-263. Among the series of MOFs, Complex 33 (LMOF-263) exhibited the best chemical and water stability and highest fluorescence quantum yield. Upon the addition of $\mathrm{Hg}^{2+}, \sim 84 \%$ of the emission intensity was quenched. $K_{\mathrm{sv}}$ of Complex 33 for $\mathrm{Hg}^{2+}$ was $459,446 \mathrm{M}^{-1}$ with the detection limit of $3.3 \mathrm{ppb}$. Moreover, the removal efficiency of Complex 33 could reach to $\sim 99.6 \%$, and the maximum $\mathrm{Hg}^{2+}$ adsorption capacity of Complex 33 was 380 mg/g. Additionally, the distribution coefficient of Complex $\mathbf{3 3}$ was determined to be $6.45 \times 10^{5} \mathrm{~mL} / \mathrm{g}$, which was high among all the reported values. In Complex 33, the electron density on the surrounding oxygen atoms elevated from the $\pi$ bonding with the $S$ atoms from sulfone group and showed a higher affinity to $\mathrm{Hg}^{2+}$ via soft acidsoft base attractions, which led ultimately to the high distribution coefficient.

\section{Modification of MOF system}

\section{Mercury sensing}

Considering the fact that MOFs are 3D crystalline materials the diffusion of mercury species through the network slows down the sensing or adsorption process. Therefore, changing the morphology of the adsorbent MOFs could be one strategy to address this issue. Chen group ${ }^{[56]}$ utilized adenine, dipicolinic acid $\left(\mathrm{H}_{2} \mathrm{DPA}\right)$ with $\mathrm{Tb}^{2+}$ to form coordination polymer nanoparticle (CPNP), namely Complex 34 (Ad/Tb/DPA CPNP). The fluorescence of Complex 34 was very weak due to the prevented energy transfer from DPA to $\mathrm{Tb}^{3+}$ by the photoinduced electron transfer from adenine to DPA. However, $\mathrm{Hg}^{2+}$ ions suppressed the energy transfer by coordinating to the $\mathrm{N}$ atoms of the adenine linkers, consequently, enhancing the fluorescence of Complex 34 by $\sim 5$ fold. In a mixed solution with $\mathrm{Cr}^{3+}$, $\mathrm{Co}^{2+}, \mathrm{Ni}^{2+}, \mathrm{Fe}^{2+}, \mathrm{Mn}^{2+}, \mathrm{Cd}^{2+}, \mathrm{Fe}^{3+}, \mathrm{Zn}^{2+}, \mathrm{Ag}^{+}, \mathrm{Cu}^{2+}, \mathrm{Pb}^{2+}, \mathrm{Mg}^{2+}$ and $\mathrm{Hg}^{2+}$, the interference of other cations was significantly weaker than that of $\mathrm{Hg}^{2+}$. Moreover, Complex 32 exhibited a detection limit of $0.2 \mathrm{nM}$.

In Yang's study, ${ }^{[57]}$ Complex $35\left(\left[\mathrm{Eu}_{2}(\mathrm{bqdc})_{3}\left(\mathrm{H}_{2} \mathrm{O}\right)(\mathrm{DMF})_{3}\right]_{n}\right)$ was developed in the form of film to sense $\mathrm{Hg}^{2+}$. They used electrodeposition in combination with subsequent solvothermal synthesis to fabricate Complex 35 consisting of $\mathrm{Eu}^{3+}$ and 2,2'-biquinoline-4,4'-dicarboxylate with uncoordinated pyridyl $\mathrm{N}$ atoms. Upon the addition of $\mathrm{Hg}^{2+}$, the chelating of $\mathrm{Hg}^{2+}$ to the pyridyl $\mathrm{N}$ atoms of the linkers quenched the luminescence. Meanwhile, ions, such as $\mathrm{Na}^{+}, \mathrm{K}^{+}, \mathrm{Mg}^{2+}, \mathrm{Ca}^{2+}, \mathrm{Zn}^{2+}, \mathrm{Cd}^{2+}$, showed no significant influence on the intensity of the film. Complex 35 had the diffusion coefficient of $\mathrm{Hg}^{2+} 4.93 \times 10^{-15}$ $\mathrm{m}^{2} / \mathrm{s}$ (calculated from Crank's method) and the detection limit of $1 \times 10^{-8} \mathrm{M}$.

In spite of fine tuning the morphology, efforts were also spent on utilizing different solvents in the sensing system. For example, Long, Hou, Sepaniak, and coworkers ${ }^{[58]}$ adopted Complex 36 (MIL-53-Fe) and $\mathrm{CCl}_{4}$ (the dispersant) as the platform to determine $\mathrm{CH}_{3} \mathrm{Hg}^{+}$. Complex 36 displayed fluorescence emission at $455 \mathrm{~nm}$ with excitation at $292 \mathrm{~nm}$. Among the treatments of $\mathrm{Hg}^{2+}, \mathrm{CH}_{3} \mathrm{Hg}^{+}$, $\mathrm{EtHg}^{+}$, and $\mathrm{PhHg}^{+}$to Complex 36 with $\mathrm{CCl}_{4}$, only $\mathrm{CH}_{3} \mathrm{Hg}^{+}$increased the fluorescence signal with a 
detection limit of $0.36 \mathrm{ppb}$. No significant change of fluorescence intensity of Complex 36 was observed when $\mathrm{Ag}^{+}, \mathrm{Al}^{3+}$, $\mathrm{Ca}^{2+}, \mathrm{Cd}^{2+}, \mathrm{Co}^{2+}, \mathrm{Cr}^{3+}, \mathrm{Cu}^{2+}, \mathrm{Fe}^{3+}, \mathrm{K}^{+}, \mathrm{Mg}^{2+}, \mathrm{Mn}^{2+}, \mathrm{Na}^{+}, \mathrm{Ni}^{2+}$, $\mathrm{Pb}^{2+}, \mathrm{Zn}^{2+}, \mathrm{Cl}^{-}, \mathrm{SO}_{4}{ }^{2-}$, or $\mathrm{NO}_{3}{ }^{-}$was introduced individually.

In another example, a dual-solvent sensing system with fast response was developed for Complex 37 (TMU-34), which consisted of zinc paddle-wheel $\mathrm{Zn}_{2}(\mathrm{COO})_{4}$, 4,4'-oxybis-(benzoate $\mathrm{OBA}^{2-}$ ) and 3,6-di(pyrindin-4-yl)-1,2,4,5-tetrazine (DPT) linkers. ${ }^{[59]}$ Taking advantage of the feasibility of tetrazine in the field of sensing, the researchers found the emission peaks of Complex $37(618 \mathrm{~nm})$ enhanced with the increasing polarity of solvent. However, a red shift of photoluminescence emission was observed for Complex $\mathbf{3 7}$ in water compared to that in acetonitrile, which might be caused by the hydrogen bonding between water and nitrogen of tetrazine moieties. This shift promised Complex $\mathbf{3 7}$ for cation sensing. In particular, the photoluminescence emission spectra of Complex 37 in presence of $\mathrm{Hg}^{2+}$ displayed $90 \%$ quenching in acetonitrile but $243 \%$ enhancement in water, respectively (Figure 2). Due to the distinct influence on the emission peaks in two different solvents, the author proposed to use $2 \mathrm{D}$ transduction to eliminate the interference of other cations and improve ultimately the sensitivity of $\mathrm{Hg}^{2+}$. As a result, the response time for Complex 37 for $\mathrm{Hg}^{2+}$ sensing was $15 \mathrm{~s}$.
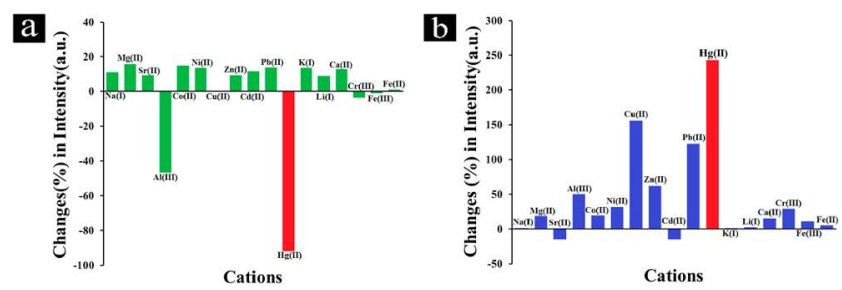

Figure 2 (a) Effects of cations on the photoluminence peak of Complex 37 at $618 \mathrm{~nm}$ upon excitation at $458 \mathrm{~nm}$ in acetonitrile. (b) Effects of cations on the photoluminence peak at $648 \mathrm{~nm}$ of Complex 37 upon excitation at $504 \mathrm{~nm}$ in water. ${ }^{[59]}$

Chi group ${ }^{[60]}$ demonstrated another strategy to functionalize bio-MOF-1 with $\mathrm{Ru}(\mathrm{bpy})_{3}{ }^{2+}$ in situ to obtain Complex 38 . In Complex 38 , the $\mathrm{Ru}(\mathrm{bpy})_{3}{ }^{2+}$ was well-dispersed in the framework and led to a strong red fluorescence under the UV or blue light. Interestingly, only $\mathrm{Hg}^{2+}$ ions triggered the release of $\mathrm{Ru}(\mathrm{bpy})_{3}{ }^{2+}$ in the presence of $\mathrm{H}^{+}$, comparing to other aqueous mixtures of $\mathrm{Li}^{+}, \mathrm{Na}^{+}, \mathrm{K}^{+}, \mathrm{NH}_{4}^{+}, \mathrm{Mg}^{2+}, \mathrm{Ca}^{2+}, \mathrm{Ba}^{2+}, \mathrm{Cu}^{2+}, \mathrm{Cd}^{2+}$, $\mathrm{Pb}^{2+}, \mathrm{Mn}^{2+}, \mathrm{Ni}^{2+}, \mathrm{Co}^{2+}, \mathrm{Fe}^{2+}, \mathrm{Fe}^{3+}$ and $\mathrm{CH}_{3} \mathrm{Hg}^{+}$. The increasing concentration of $\mathrm{Hg}^{2+}$ accelerated significantly the release of $\mathrm{Ru}(\mathrm{bpy}){ }_{3}{ }^{2+}$ with the molar ratio of $\mathrm{Ru}(\mathrm{bpy})_{3}{ }^{2+}$ to $\mathrm{Hg}^{2+}$ range from $\sim 103$ to $\sim 106$. This fast release was suspected to occur mainly based on the disassembly of Complex 38 resulted from the higher affinity of adenine towards $\mathrm{Hg}^{2+}$. This ion-responsible release made Complex $\mathbf{3 8}$ an excellent ultrasensitive sensor of $\mathrm{Hg}^{2+}$ with the LOD of $5.3 \times 10^{-13} \mathrm{M}$. The preconcentration of $\mathrm{Hg}^{2+}$ from the water sample of Min River using Complex 38 was consistent with the results obtained using ICP-MS.

\section{Mercury removal}

Additionally, Wang and coworkers ${ }^{[61]}$ took advantage of the strategy of in situ ligand formation to embed an anionic framework Complex 39 (BUT-52) with $\mathrm{Cu}_{6} \mathrm{~S}_{6}$ cluster (Figure 3). The $\mathrm{Cu}$ atom was trigonal coordinated to one pyridyl $\mathrm{N}$ atom and two $\mathrm{S}$ atoms from three independent linkers to produce a $\mathrm{Cu}_{6} \mathrm{~S}_{6}$ unit. Furthermore, the indium atoms in Complex 39 were coordinated with four carboxylate oxygens in a distorted tetrahedral geometry to make the classic $\ln (\mathrm{COO})_{4}{ }^{-}$unites, leading to an anionic framework. The richness of sulfur enabled Complex 39 with strong affinity toward mercury, and more than $92 \%$ mercury in methanol could be removed.

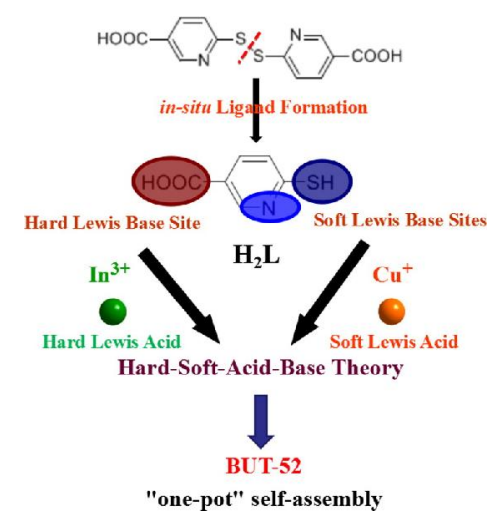

Figure 3 Synthetic scheme for the rational design of Complex 39 on the basis of $\mathrm{In}^{3+}, \mathrm{Cu}^{+}$, and the in situ synthesized ligand involving carboxylate, pyridyl, and thiol groups. ${ }^{[61]}$

\section{Post-synthetic Modification solely on MOFs}

\section{Mercury sensing}

Lang and Li groups ${ }^{[62]}$ demonstrated that the photochemical [2+2] addition of olefinic bonds in MOFs could help improve the sensing ability for $\mathrm{Hg}^{2+}$. In this work, the previously reported Complex 40, $\{[\mathrm{Cd}(\text { ppene })(1,4-\mathrm{BDC})] \cdot \mathrm{MeCN}\}_{n}$ (ppene = 4-pyrpoly-2-ene), was exposed under the UV light radiation and turned to the cylcobutane-appended MOF $\left\{\mathrm{Cd}_{2}\right.$ (4-tp-3-lad)$\left.(1,4-\mathrm{BDC})_{2} \mathrm{MeCN}\right\}_{n}$, where 4-tp-3-lad was 2,3,5,6-tetra(pyridn4-yl)-bicycl[2.2.0]hexane, in a single-crystal-to-single-crystal transformation. The olefinic Complex $\mathbf{4 0}$ was not capable to be used to probe $\mathrm{Hg}^{2+}$ in aqueous solution. However, the change from the olefinic bonds to the cyclobutane rings upon radiation made the sensing of $\mathrm{Hg}^{2+}$ possible. The emission peak not only blue-shifted but also displayed an enhancement of the intensity. Mercury removal

Zhu and coworkers ${ }^{[63]}$ grafted rationally thiol groups into the unsaturated $\mathrm{Cu}$ sites of HKUST-1. Different amounts of thiol groups could be predictably controlled by the variation of the amount of thiol source dithioglycol. Among all the thiol-functionalized HKUST-1 materials, Complex 41 (MOF with $\mathrm{S}: \mathrm{Cu}=0.92$ ) displayed not only a remarkably distribution constant of $4.73 \times 10^{5} \mathrm{~mL} \cdot \mathrm{g}^{-1}$ but also the best $\mathrm{Hg}^{2+}$ adsorption with the maximum capacity of $714.29 \mathrm{mg} / \mathrm{g}$ and the removal efficiency of $99.79 \%$.

As mentioned previously, harsh post-synthetic modifications are likely to be done on stable MOFs for the sake of retaining the framework. Davis and coworkers ${ }^{[64]}$ post-synthetically introduced thiourea, isothicyanate and isocyanate functional groups to UiO-66- $\mathrm{NH}_{2}$ and constructed six different UiO-66 derivatives (UiO-66-NCO, UiO-66-NHC(S)NHPh, UiO66-NHC(S)NHMe, UiO-66-NCS, UiO-66-NHC(S)NHtBu, and UiO-66-NHC(S)NHCy). Among all those functionalized MOFs, Complex 42 (UiO-66-NHC(S)NHMe) removed markedly $99.4 \%$ of mercury ( $v s$. $\sim 8 \%$ for UiO-66 and $\sim 32 \%$ for UiO-66- $-\mathrm{NH}_{2}$ ). The maximum $\mathrm{Hg}^{2+}$ adsorption capacity of Complex 42 was 769 $\mathrm{mg} / \mathrm{g}$.

Tandem post-synthetic modifications has also been demonstrated in another stable MOF Cr-MIL-101. Dong, Liu and coworkers ${ }^{[65]}$ explored the utilization of post-synthetically modification of Cr-MIL-101- $\mathrm{N}_{2}^{+} \mathrm{BF}_{4}^{-}$, which was prepared by mixing Cr-MIL-101- $\mathrm{NH}_{2}$ in an acidic solution followed by an addition of $\mathrm{NaNO}_{2}$, to enhance the adsorption of $\mathrm{Hg}^{2+}$. Then they converted the diazonium salt to alkenyl-derived MOF, Cr-MIL-101-A1-6, by means of a carbon-carbon bond-forming reaction with $\mathrm{Pd}(\mathrm{OAc})_{2}$ as the catalyst. They further converted Cr-MIL-101-A4 (the alkenyl and benzyl alcohol-derived MOF) to 
Complex 43 (Cr-MIL-101-AS), which was turn the alkenyl groups to the benzyl thiol groups. Notably, Complex 43 displayed a remarkable $\mathrm{Hg}^{2+}$ removal efficiency of $99.3 \%$ under 6 $\mathrm{h}$ for at least two times without losing any activity.

\section{Construction of MOF-based composites}

\section{Mercury sensing}

Chen group ${ }^{[66]}$ utilized the inner filter effect in the design of an Eu/IPA MOF nanoparticle (NP) system using $\mathrm{Eu}^{3+}$ as the fluorophore, and isophthalic acid (IPA) as the bridging ligand. Post-synthetically, they introduced dicarbolic acid (Im) to construct Complex 44. Im had a strong absorption band overlapping with the excitation spectrum of the MOF NP and would filter out the energy transfer from ligand to $\mathrm{Eu}^{3+}$ and decrease significantly the strong red fluorescence of the NP. Interestingly, the further addition of $\mathrm{Hg}^{2+}$ into Complex 44 resulted in a stable $\mathrm{Hg} / \mathrm{lm}$ complex, which led to the complete fluorescence recovery within 2 min without any structural change of the NP. At $\mathrm{pH}=7$, the detection limit of Complex 44 was estimated to $\sim 2$ $\mathrm{nM}$. Under the similar experimental measurements, none of those common ions $\left(\mathrm{Ag}^{+}, \mathrm{K}^{+}, \mathrm{Na}^{+}, \mathrm{Mg}^{2+}, \mathrm{Pb}^{2+}, \mathrm{Zn}^{2+}, \mathrm{Cd}^{2+}, \mathrm{Ca}^{2+}\right.$, $\mathrm{Ni}^{2+}, \mathrm{Co}^{2+}, \mathrm{Mn}^{2+}, \mathrm{Ce}^{3+}, \mathrm{Fe}^{3+}, \mathrm{Cr}^{3+}$ and $\mathrm{Al}^{3+}$ ), amino acid, glucose, and ascorbic acids, enhanced significantly the fluorescence. The following application of Complex $\mathbf{4 4}$ as the turn-on sensors in the urine samples exhibited more than 95\% recovery.

Yan and coworkers ${ }^{[67]}$ constructed a dual emissive MOF composite by utilizing the optical active carbon dots (CDs) in MOF-253 in one-pot synthesis, which consisted of 1D aluminum chain with 2,2'-bipyridine-5,5'-dicarboxylic forming 1D rhombic channels. They post-synthetically introduced $\mathrm{Eu}^{3+}$ to produce Complex $45\left(\mathrm{Eu}^{3+} / \mathrm{CD} @ M O F-253\right)$. The in situ encapsulation of CDs in MOF-253 enabled blue florescent framework with an emission peak at $453 \mathrm{~nm}$ and excitation of $360 \mathrm{~nm}$. Upon the introduction of $\mathrm{Eu}^{3+}$, a second characteristic of $\mathrm{Eu}^{3+}\left({ }^{5} \mathrm{D}_{0} \rightarrow{ }^{7} \mathrm{~F}_{2}\right)$ at $614 \mathrm{~nm}$ was monitored with excitation of $340 \mathrm{~nm}$. Complex 45 displayed both photostablity at room temperature for $9 \mathrm{~d}$ and $\mathrm{pH}$ stability in aqueous solution between $\mathrm{pH} 4-9$, which promised Complex 45 a good candidate for fluorescence sensing. When $\mathrm{Hg}^{2+}$ ions were introduced to the composite, the mercury coordinated to the functional group of CDs and thus changed the surface traps or electron-hole recombination annihilation via electron/energy transfer. Ultimately, the fluorescence of CDs was quenched efficiently with the evidence of decreasing intensity of blue fluorescence at 453 $\mathrm{nm}$, wherein the solution turned from blue to red under UV light. When Complex $\mathbf{4 5}$ was immersed in the aqueous solution with different concentrations of $\mathrm{Hg}^{2+}$, the fluorescent color changed visibly from blue to faint blue, dark red and finally red with an increasing amount of $\mathrm{Hg}^{2+}$ under UV radiation $(3 \mathrm{mg} / \mathrm{g}$ composite). Among all the potential interference ions $\left(\mathrm{Zn}^{2+}, \mathrm{Ni}^{2+}, \mathrm{Na}^{+}\right.$, $\mathrm{Mn}^{2+}, \mathrm{Mg}^{2+}, \mathrm{K}^{+}, \mathrm{Pb}^{2+}, \mathrm{Cu}^{2+}, \mathrm{Fe}^{3+}, \mathrm{Ca}^{2+}, \mathrm{Cd}^{2+}, \mathrm{Fe}^{2+}, \mathrm{Al}^{3+}, \mathrm{Cr}^{3+}$, $\mathrm{Co}^{2+}$, and $\mathrm{Hg}^{2+}$ ), significant quenching effect was only observed in the presence of $\mathrm{Hg}^{2+}$ and led to a red-colored fluorescence emission. The researcher also reported the use of Complex 45 to remove the mercury in environmental water samples (river water, fountain water, and tap water), and the removal efficiencies were all above $90.0 \%$.

Additionally, Azzazy group ${ }^{[68]}$ loaded dithizone (DZ) into UiO-66 to fabricate an efficient $\mathrm{Hg}^{2+}$ sensor-Complex 46 . In the inclusion of DZ decreased the BET surface to $421 \mathrm{~m}^{2} \cdot \mathrm{g}^{-1}$ ( $v s$. UiO-66 $\left.839 \mathrm{~m}^{2} \cdot \mathrm{g}^{-1}\right)$. The detection limit of Complex 46 reached $0.52 \mathrm{nM}$ at $\mathrm{pH}=9.5$.

Due to the fact that $\mathrm{Hg}^{2+}$ binds specifically to thymine-thymine (T-T) mismatched based pair, the hybridization of T-rich fluorophore (FAM) single stranded DNA and UiO-66, leading to Complex 47, was demonstrated as an excellent mercury sensor (Figure 4). ${ }^{[69]}$ The FAM had fluorescence at 518 $\mathrm{nm}$ under excitation at $480 \mathrm{~nm}$, in which no shift was observed by either $\mathrm{Hg}^{2+}$ or UiO-66- $\mathrm{NH}_{2}$. In Complex 47, FAM bonded to UiO-66- $\mathrm{NH}_{2}$ through $\pi-\pi$ stacking and hydrogen-bonding between the nucleotide bases of DNA and the aromatic ring in UiO-66- $\mathrm{NH}_{2}$, consequently quenching the fluorescence ( 75\%). The introduction of $\mathrm{Hg}^{2+}(10.0 \mu \mathrm{M})$ had better affinity to coordinate to FAM, inducing the formation of helical structure and blocking the photoinduced electron transfer, and enhanced eventually the fluorescence by more than two fold. Therefore, the monitoring of the fluorescence of Complex $\mathbf{4 7}$ indicated the presence of $\mathrm{Hg}^{2+}$. In the range of $0.1-10.0 \mu \mathrm{M} \mathrm{of} \mathrm{Hg}^{2+}$, the enhancement improved along with the increasing concentration of $\mathrm{Hg}^{2+}$. In addition, Complex $\mathbf{4 7}$ showed not only a detection limit of $17.6 \mathrm{nM}$ but also a high selectivity of $\mathrm{Hg}^{2+}$ over other metal ions $\left(\mathrm{Ca}^{2+}, \mathrm{Cd}^{2+}, \mathrm{Co}^{2+}, \mathrm{Cu}^{2+}, \mathrm{Fe}^{2+}, \mathrm{Fe}^{3+}, \mathrm{Mg}^{2+}, \mathrm{Mn}^{2+}, \mathrm{Ni}^{2+}\right.$, $\mathrm{Pb}^{2+}$ ).

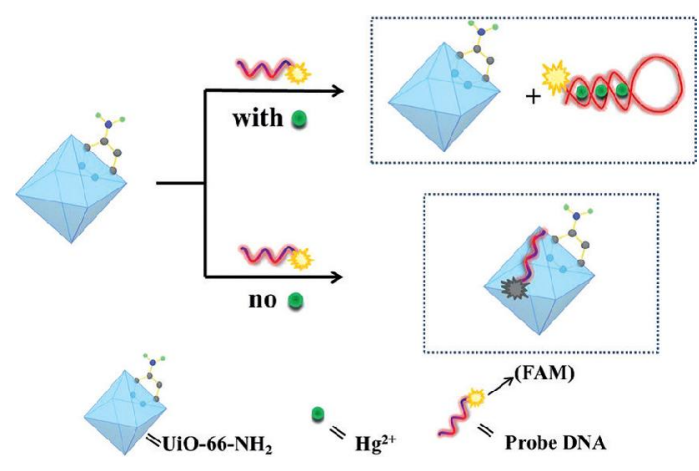

Figure 4 Schematic concept of the fluorescent sensing system of Complex 47. ${ }^{[69]}$

\section{Mercury removal}

Sohrabi ${ }^{[70]}$ fabricated a nanocomposite Complex 48 (SH@ $\left.\mathrm{SiO}_{2} @ \mathrm{HKUST}-1\right)$. This composite was composed of the thiolfunctionalized silica nanoparticles and the novel MOF HKUST-1. The Langmuir adsorption study indicated that Complex $\mathbf{4 8}$ had a maximum $\mathrm{Hg}^{2+}$ capacity of $210 \mathrm{mg} / \mathrm{g}$ at the optimal adsorption condition and a LOD of $20 \mathrm{pg} \cdot \mathrm{mL}^{-1}$ with the standard derivation of $<7.2 \%$. Complex $\mathbf{4 8}$ demonstrated generally more than $90 \%$ of the recovery of mercury from real samples of tap water, waste water, sea water, Kan River, Sediment, and fish.

In another study, the researchers utilized the self-template method to fabricate a magnetic MOF composite Complex 49 $\left(\mathrm{Fe}_{3} \mathrm{O}_{4} @ \mathrm{SiO}_{2} @ \mathrm{HKUST}-1\right)$ in the form of the core-shell architecture. ${ }^{[71]}$ The thickness of the MOF shell could be feasibly controlled by the variation of the metal precursor (in this case the amount of copper). To enhance the removal efficiency of mercury, Complex 49 was further post-synthetically modified with bismuthiol (Bi-I). The existence of $\mathrm{Fe}_{3} \mathrm{O}_{4} @ \mathrm{SiO}_{2}$ nanoparticles made the composite superparamagnetic with the saturation magnetization of $8 \mathrm{emu} \cdot \mathrm{g}^{-1}$. The Bi-I functionalized Complex 49 displayed $>99 \%$ removal efficiency in a mixed solution of $\mathrm{Hg}^{2+}$ with other seven common ions in water at $\mathrm{pH}=3(23 \%$ $\mathrm{Pb}^{2+}$ and $\left.4.5 \% \mathrm{Cr}^{3+}\right)$. The maximum mercury capacity of the Bi-I functionalized Complex 49 was $264 \mathrm{mg} / \mathrm{g}$.

Ferrando-Soria, Armentano and coworkers ${ }^{[72]}$ synthesized a water-stable MOF Complex $50 \quad\left(\mathrm{Ca}^{\prime \prime} \mathrm{Cu}_{6}{ }_{6}\left[(\mathrm{~S}, \mathrm{~S})-\right.\right.$-methox $_{3^{-}}$ $\left.(\mathrm{OH})_{2}\left(\mathrm{H}_{2} \mathrm{O}\right)\right)$, which was constructed from chiral bis[(S)-methionine]oxalyl diamide ligand and a mixture of calcium and copper ions. Complex $\mathbf{5 0}$ was a honeycomb-like network with hexagonal channels of $\sim 0.3 \mathrm{~nm}$, which were highly decorated with flexible thioether chains from the methionine part of linkers. Single crystal XRD data displayed that a two-step adsorption of mercury, in which three $\mathrm{HgCl}_{2}$ molecules per formula unit were 
General Chemistry

initially adsorbed at an extreme fast rate and then a slow loading until five molecules were adsorbed. Due to the poor solubility and weak affinity of $\mathrm{CH}_{3} \mathrm{HgCl}$ in the solvent of water/methanol, the adsorption of $\mathrm{CH}_{3} \mathrm{HgCl}$ was relatively slow and ended up with one molecule per formula unit. In Complex 50, the sulfur atoms of the methionine units showed a good affinity to the mercury species. As a result, Complex $\mathbf{5 0}$ demonstrated a good selectivity of $\mathrm{Hg}^{2+}$ over other common ions in water, such as $\mathrm{Na}^{+}, \mathrm{K}^{+}, \mathrm{Ca}^{2+}, \mathrm{Mg}^{2+}, \mathrm{HCO}_{3}^{-}, \mathrm{Cl}^{-}$, and $\mathrm{NO}_{3}^{-}$. A MOF-polymer pellet was made by mixing Complex $\mathbf{5 0}$ with a commercial polymer for the sake of better stability. Remarkably, this pellet adsorbed $99.95 \% \mathrm{HgCl}_{2}$ and $\sim 99.0 \% \mathrm{CH}_{3} \mathrm{HgCl}$ in the aqueous solution in a reversible manner over $2.8 \mathrm{~d}$ and decreased the level of $\mathrm{Hg}^{2+}$ and $\mathrm{CH}_{3} \mathrm{Hg}^{+}$from $10 \mathrm{ppm}$ to $5 \mathrm{ppb}$ and $27 \mathrm{ppb}$, respectively. The maximum mercury adsorption was calculated to be $5 \mathrm{mg} / \mathrm{g}$ pellet.

In the light of $\mathrm{Mn}-\mathrm{Ce}$ catalysts facilitate the $\mathrm{Hg}^{0}$ oxidation and the selective catalytic reduction of NO from the flue gas, Shen group ${ }^{[73]}$ designed a Mn-Ce loaded composite Complex 51 (MnCe@UiO-67). Interestingly, the researchers also found either the introduction of $\mathrm{NO}$ or a small amount of $\mathrm{O}_{2}$ in the simulated flue gas promoted the $\mathrm{Hg}^{0}$ removal of Complex $\mathbf{5 1}$, while the presence of $\mathrm{NH}_{3}$ inhibited the removal. Under an optimal condition of $300{ }^{\circ} \mathrm{C}$ in the presence of $500 \mathrm{ppm}$ NO in the flue gas, the $\mathrm{Hg}^{0}$ removal efficiency of Complex 51 reached above $95 \%$. In addition, the gradually decreasing of $\mathrm{Ce}^{3+} / \mathrm{Ce}^{4+}$ ratio during extended reaction time implied the consumption of adsorption oxygen in the composite. As a result, the removal efficiency decreased over the reaction time, since the oxygen, serving as the oxidant for $\mathrm{Hg}^{0}$, was consumed.

\section{Conclusion and Outlook}

Overall, all those studies approve that MOF-based materials promise greatly the mercury sensing and removal. However, there are still some concerns remaining unaddressed. (1) Some of the aforementioned examples reveal the importance of temperature in mercury adsorption. Therefore, it is important to standardize the adsorption condition $\left(25^{\circ} \mathrm{C}\right.$ and $1 \mathrm{~atm}$ as an example) for mercury species from the consideration of practical uses. (2) Many of those MOF-based materials are capable for one-time use, and only a few show capability for multiple uses. In this case, the reusability should be considered in order to minimize the cost when commercializing the MOF-based adsorbents. To address this concern, water-stable MOFs (usually constructed from high-valent metal ions) are good candidates to expand the working span of those materials for the sake of good recyclability. (3) Among all the reported MOF-based materials for mercury removal, less than ten materials were applied to extract/preconcentrate mercury from real samples. In the future, it will be straightforward if the reports could include the application of new materials for the mercury removal from real samples, biomass, water and soil samples to name a few. (4) The presence of sulfur- or nitrogen-containing groups with exposed sulfur or nitrogen atoms in the MOF-based materials truly enhance the overall mercury capacity in most cases. Continuous efforts on incorporation of more adsorption sites with exposed sulfur and nitrogen atoms (polyamines, cyclam and its carboxylate derivatives, thiophene, thiol chains, acylamide for example) on the framework should also be spent to maximize the overall capacity and removal efficiency. (5) In the application of methane, hydrogen, and carbon dioxide storages, significant amount of analysis on adsorption enthalpy, interaction sites and binding energy obtained from computation calculation provide meaningful guidance in the design of high-performance adsorbents. ${ }^{[9]}$ So far, only a handful of computational calculations have focused on the application of MOF for mercury sensing and adsorption. ${ }^{[53,74]}$ Similar computational support should be provided in designing new MOF-based materials with specific targets, incorporation of more adsorption sites on the framework for example, of mercury sensing and adsorption. Additionally, many reports ascribed the quenching or enhancing effect for mercury sensing to the ligand-metal and/or metal-ligand electron transfer. No systematic investigation demonstrated detailed insights about the sensing mechanism. In this case, computational simulation may provide such aids to help understand the sensing and/or adsorption mechanism. (6) In one of the previous study, the researchers packed a MOF-filled column to test the removal ability from real samples. ${ }^{[51]}$ Similar endeavors should be encouraged from the scaling-up point of view. As some of the aforementioned MOF-based materials displayed fast response to the mercury species, it will be significant to adopt such a MOF-filled column in a real flow line, where MOFs are used to sense the mercury species. (7) Currently, a booming area of MOFs focuses on the use of MOF-based materials for cancer treatment or drug carrier. As the mercury species accumulate in the food chain, similar biomedical studies could also be introduced on applying MOFs as "nanocustodian" to selectively extract mercury from blood or proteins and then take the mercury trash out. Mercury pollution is everywhere and harming our life in every second. Thereby, there is an urgent need to remove those stable mercury species from nature in an affordable way. As the exploration of MOF booms up, such a useful MOF-based mercury remover will be developed in the near further.

\section{Acknowledgement}

This work was partially funded by CSU-Pueblo's C-BASE (Communities to Build Active STEM Engagement) grant from the US Department of Education (PR/Award \# P031C160025). The authors also thank the Department of Chemistry in Colorado State University-Pueblo for its additional support.

\section{Supporting Information}

Supporting information for this article is available on the WWW under www.genchemistry.org/EN/10.21127/yaoyigc201 80003.

\section{References}

[1] Wan Ngah, W. S.; Hanafiah, M. A. K. M. Bioresource Technol. 2008, 99, 3935.

[2] Kumar, P.; Guliants, V. V. Micropor. Mesopor. Mater. 2010, $132,1$.

[3] Dąbrowski, A.; Hubicki, Z.; Podkościelny, P.; Robens, E. Chemosphere 2004, 56, 91.

[4] Huebra, M.; Elizalde, M. P.; Almela, A. Hydrometallurgy 2003, 68, 33.

[5] Gupta, V. K.; Carrott, P. J. M.; Ribeiro Carrott, M. M. L.; Suhas Crit. Rev. Environ. Sci. Technol. 2009, 39, 783.

[6] Adil, K.; Belmabkhout, Y.; Pillai, R. S.; Cadiau, A.; Bhatt, P. M.; Assen, A. H.; Maurin, G.; Eddaoudi, M. Chem. Soc. Rev. 2017, 46, 3402.

[7] Bobbitt, N. S.; Mendonca, M. L.; Howarth, A. J.; Islamoglu, T.; Hupp, J. T.; Farha, O. K.; Snurr, R. Q. Chem. Soc. Rev. 2017, 46, 3357.

[8] DeCoste, J. B.; Peterson, G. W. Chem. Rev. 2014, 114, 5695.

[9] Evans, J. D.; Jelfs, K. E.; Day, G. M.; Doonan, C. J. Chem. Soc. Rev. 2017, 46, 3286

[10] Huxford, R. C.; Rocca, J. D.; Lin, W. Curr. Opin. Chem. Biol. 2010 14, 262.

[11] Lee, J.; Farha, O. K.; Roberts, J.; Scheidt, K. A.; Nguyen, S. T.; Hupp, J. T. Chem. Soc. Rev. 2009, 38, 1450. 
[12] Li, J.-R.; Sculley, J.; Zhou, H.-C. Chem. Rev. 2012, 112, 869.

[13] Liu, J.; Thallapally, P. K.; McGrail, B. P.; Brown, D. R.; Liu, J. Chem. Soc. Rev. 2012, 41, 2308.

[14] Lustig, W. P.; Mukherjee, S.; Rudd, N. D.; Desai, A. V.; Li, J.; Ghosh, S. K. Chem. Soc. Rev. 2017, 46, 3242.

[15] Murray, L. J.; Dinca, M.; Long, J. R. Chem. Soc. Rev. 2009, 38 , 1294.

[16] Rogge, S. M. J.; Bavykina, A.; Hajek, J.; Garcia, H.; Olivos-Suarez, A. I.; Sepulveda-Escribano, A.; Vimont, A.; Clet, G.; Bazin, P.; Kapteijn, F.; Daturi, M.; Ramos-Fernandez, E. V.; Llabres i Xamena, F. X.; Van Speybroeck, V.; Gascon, J. Chem. Soc. Rev. 2017, 46, 3134.

[17] Stassen, I.; Burtch, N.; Talin, A.; Falcaro, P.; Allendorf, M.; Ameloot, R. Chem. Soc. Rev. 2017, 46, 3185.

[18] Van de Voorde, B.; Bueken, B.; Denayer, J.; De Vos, D. Chem. Soc. Rev. 2014, 43, 5766.

[19] Wang, C.-C.; Li, J.-R.; Lv, X.-L.; Zhang, Y.-Q.; Guo, G. Energ. Environ. Sci. 2014, 7, 2831.

[20] Zhang, T.; Lin, W. Chem. Soc. Rev. 2014, 43, 5982.

[21] Lu, W.; Wei, Z.; Gu, Z.-Y.; Liu, T.-F.; Park, J.; Park, J.; Tian, J.; Zhang, M.; Zhang, Q.; Gentle lii, T.; Bosch, M.; Zhou, H.-C. Chem. Soc. Rev. 2014, 43, 5561

[22] Cohen, S. M. Chem. Rev. 2012, 112, 970.

[23] Lalonde, M.; Bury, W.; Karagiaridi, O.; Brown, Z.; Hupp, J. T.; Farha, O. K. J. Mater. Chem. A 2013, 1, 5453.

[24] Zhu, Q.-L.; Xu, Q. Chem. Soc. Rev. 2014, 43, 5468.

[25] Doherty, C. M.; Buso, D.; Hill, A. J.; Furukawa, S.; Kitagawa, S.; Falcaro, P. Acc. Chem. Res. 2014, 47, 396.

[26] Lian, X.; Fang, Y.; Joseph, E.; Wang, Q.; Li, J.; Banerjee, S.; Lollar, C.; Wang, X.; Zhou, H.-C. Chem. Soc. Rev. 2017, 46, 3386.

[27] Kitao, T.; Zhang, Y.; Kitagawa, S.; Wang, B.; Uemura, T. Chem. Soc. Rev. 2017, 46, 3108.

[28] Rubio-Martinez, M.; Avci-Camur, C.; Thornton, A. W.; Imaz, I.; Maspoch, D.; Hill, M. R. Chem. Soc. Rev. 2017, 46, 3453.

[29] Corma, A.; García, H.; Llabrés i Xamena, F. X. Chem. Rev. 2010, $110,4606$.

[30] Wu, P.; Liu, Y.; Liu, Y.; Wang, J.; Li, Y.; Liu, W.; Wang, J. Inorg. Chem. 2015, 54, 11046

[31] Wen, L.; Zheng, X.; Lv, K.; Wang, C.; Xu, X. Inorg. Chem. 2015, 54, 7133.

[32] Rachuri, Y.; Parmar, B.; Bisht, K. K.; Suresh, E. Cryst. Growth Des. 2017, 17, 1363.

[33] Chen, M.-M.; Chen, L.; Li, H.-X.; Brammer, L.; Lang, J.-P. Inorg. Chem. Front. 2016, 3, 1297.

[34] Chen, M.-M.; Zhou, X.; Li, H.-X.; Yang, X.-X.; Lang, J.-P. Cryst. Growth Des. 2015, 15, 2753.

[35] Li, W.-X.; Li, H.-X.; Li, H.-Y.; Chen, M.-M.; Shi, Y.-X.; Lang, J.-P. Cryst. Growth Des. 2017, 17, 3948.

[36] Staderini, S.; Tuci, G.; D'Angelantonio, M.; Manoli, F.; Manet, I.; Giambastiani, G.; Peruzzini, M.; Rossin, A. ChemistrySelect 2016, $1,1123$.

[37] Xia, T.; Song, T.; Zhang, G.; Cui, Y.; Yang, Y.; Wang, Z.; Qian, G. Chem. Eur. J. 2016, 22, 18429.

[38] Wang, H.-M.; Yang, Y.-Y.; Zeng, C.-H.; Chu, T.-S.; Zhu, Y.-M.; Ng, S. W. Photochem. Photobiol. Sci. 2013, 12, 1700.

[39] Xu, F.; Kou, L.; Jia, J.; Hou, X.; Long, Z.; Wang, S. Anal. Chim. Acta 2013, 804, 240.

[40] Wang, D.; Ke, Y.; Guo, D.; Guo, H.; Chen, J.; Weng, W. Sensor. Actuat. B Chem. 2015, 216, 504.

[41] Kahkha Mohammad, R.; Daliran, S.; Oveisi, A. R.; Kaykhaii, M.; Sepehri, Z. Food Anal. Methods 2017, 10, 2175.

[42] Yang, J.; Wang, Z.; Li, Y.; Zhuang, Q.; Zhao, W.; Gu, J. RSC Adv. 2016, 6, 69807.

[43] Halder, S.; Mondal, J.; Ortega-Castro, J.; Frontera, A.; Roy, P. Dalton Trans. 2017, 46, 1943.
[44] Fang, Q.-R.; Yuan, D.-Q.; Sculley, J.; Li, J.-R.; Han, Z.-B.; Zhou, H.-C. Inorg. Chem. 2010, 49, 11637.

[45] Wu, Y.; Xu, G.; Wei, F.; Song, Q.; Tang, T.; Wang, X.; Hu, Q. Micropor. Mesopor. Mater. 2016, 235, 204.

[46] Xiong, Y. Y.; Li, J. Q.; Gong, L. L.; Feng, X. F.; Meng, L. N.; Zhang, L.; Meng, P. P.; Luo, M. B.; Luo, F. J. Solid State Chem. 2017, 246, 16.

[47] Zhang, X.; Shen, B.; Zhu, S.; Xu, H.; Tian, L. J. Hazard. Mater. 2016, 320, 556.

[48] Shan, F.-S.; Lai, J.-P.; Sun, H.; Zhang, P.; Luo, C.; He, Y.-H.; Feng, H.-R. RSC Adv. 2016, 6, 66215.

[49] Zhou, X.-P.; Xu, Z.; Zeller, M.; Hunter, A. D. Chem. Commun. 2009, 5439.

[50] He, J.; Yee, K.-K.; Xu, Z.; Zeller, M.; Hunter, A. D.; Chui, S. S.-Y.; Che, C.-M. Chem. Mater. 2011, 23, 2940.

[51] Liang, L.; Chen, Q.; Jiang, F.; Yuan, D.; Qian, J.; Lv, G.; Xue, H.; Liu, L.; Jiang, H.-L.; Hong, M. J. Mater. Chem. A 2016, 4, 15370.

[52] Yee, K.-K.; Reimer, N.; Liu, J.; Cheng, S.-Y.; Yiu, S.-M.; Weber, J.; Stock, N.; Xu, Z. J. Am. Chem. Soc. 2013, 135, 7795.

[53] Wang, K.; Huang, H.; Xue, W.; Liu, D.; Zhao, X.; Xiao, Y.; Li, Z.; Yang, Q.; Wang, L.; Zhong, C. CrystEngComm 2015, 17, 3586.

[54] Luo, F.; Chen, J. L.; Dang, L. L.; Zhou, W. N.; Lin, H. L.; Li, J. Q.; Liu, S. J.; Luo, M. B. J. Mater. Chem. A 2015, 3, 9616.

[55] Rudd, N. D.; Wang, H.; Fuentes-Fernandez, E. M. A.; Teat, S. J.; Chen, F.; Hall, G.; Chabal, Y. J.; Li, J. ACS Appl. Mater. Inter. 2016, 8, 30294.

[56] Tan, H.; Liu, B.; Chen, Y. ACS Nano 2012, 6, 10505

[57] Zhu, Y.-M.; Zeng, C.-H.; Chu, T.-S.; Wang, H.-M.; Yang, Y.-Y.; Tong, Y.-X.; Su, C.-Y.; Wong, W.-T. J. Mater. Chem. A 2013, 1, 11312.

[58] Jia, J.; Xu, F.; Long, Z.; Hou, X.; Sepaniak, M. J. Chem. Commun. 2013, 49, 4670.

[59] Razavi, S. A. A.; Masoomi, M. Y.; Morsali, A. Inorg. Chem. 2017, $56,9646$.

[60] Lin, X.; Luo, F.; Zheng, L.; Gao, G.; Chi, Y. Anal. Chem. 2015, 87 , 4864.

[61] Han, Y.; Zheng, H.; Liu, K.; Wang, H.; Huang, H.; Xie, L.-H.; Wang L.; Li, J.-R. ACS Appl. Mater. Inter. 2016, 8, 23331.

[62] Gong, W.-J.; Ren, Z.-G.; Li, H.-X.; Zhang, J.-G.; Lang, J.-P. Cryst. Growth Des. 2017, 17, 870.

[63] Ke, F.; Qiu, L.-G.; Yuan, Y.-P.; Peng, F.-M.; Jiang, X.; Xie, A.-J.; Shen, Y.-H.; Zhu, J.-F. J. Hazard. Mater. 2011, 196, 36.

[64] Saleem, H.; Rafique, U.; Davies, R. P. Micropor. Mesopor. Mater. 2016, 221, 238.

[65] Liu, T.; Che, J.-X.; Hu, Y.-Z.; Dong, X.-W.; Liu, X.-Y.; Che, C.-M. Chem. Eur. J. 2014, 20, 14090.

[66] Li, Q.; Wang, C.; Tan, H.; Tang, G.; Gao, J.; Chen, C.-H. RSC Adv. 2016, 6, 17811.

[67] Xu, X.-Y.; Yan, B. Journal of Materials Chemistry C 2016, 4, 1543.

[68] Shahat, A.; Hassan, H. M. A.; Azzazy, H. M. E. Anal. Chim. Acta 2013, 793, 90.

[69] Wu, L.-L.; Wang, Z.; Zhao, S.-N.; Meng, X.; Song, X.-Z.; Feng, J.; Song, S.-Y.; Zhang, H.-J. Chem. Eur. J. 2016, 22, 477.

[70] Sohrabi, M. R. Microchim. Acta 2014, 181, 435.

[71] Huang, L.; He, M.; Chen, B.; Hu, B. J. Mater. Chem. A 2015, 3, 11587.

[72] Mon, M.; Lloret, F.; Ferrando-Soria, J.; Martí-Gastaldo, C. Armentano, D.; Pardo, E. Angew. Chem. Int. Ed. 2016, 55, 11167.

[73] Zhang, X.; Shen, B.; Shen, F.; Zhang, X.; Si, M.; Yuan, P. Chem. Eng. J. 2017, 326, 551.

[74] Liu, Y.; Li, H.; Liu, J. Fuel 2016, 184, 474.

Received January 18, 2018

Accepted February 13, 2018 